\title{
Functional hypogonadism in middle-aged and older men: testosterone treatment or not?
}

\author{
Mathis Grossmann (101,2 and Thomas Hugh Jones ${ }^{3,4}$ \\ ${ }^{1}$ Department of Medicine, Austin Health, The University of Melbourne, Victoria, Australia, ${ }^{2}$ Department of \\ Endocrinology, Austin Health, Heidelberg, Victoria, Australia, ${ }^{3}$ Robert Hague Centre for Diabetes and Endocrinology, \\ Barnsley Hospital NHS Foundation Trust, Barnsley, UK, and ${ }^{4}$ Department of Oncology and Metabolism, School of \\ Medicine and Biomedical Sciences, University of Sheffield, Sheffield, UK
}

Correspondence

should be addressed

to M Grossmann

Email

mathisg@unimelb.edu.au

\begin{abstract}
Clinicians commonly encounter middle-aged and older men who present with functional hypogonadism, that is, with clinical features compatible with androgen deficiency and lowered serum testosterone, but without evidence of organic hypothalamic-pituitary-testicular axis pathology. Whether, and when, testosterone therapy should be offered to such men remains uncertain and controversial, in part due to the lack of definitive evidence regarding long-term patient-important health outcomes with testosterone treatment. In this debate, we address this controversy and provide two opposing points of view on the role of testosterone treatment in older men with functional hypogonadism.
\end{abstract}

\section{Introduction}

The diagnosis of male hypogonadism requires both clinical evidence of androgen deficiency and the presence of repeatedly reduced serum testosterone concentrations, measured in the morning, in the fasted state, with a reliable assay (1). Hypogonadism is classified as either organic, that is, due to medical disease of the hypothalamic-pituitary-testicular axis (HPT), or as functional (2). Functional hypogonadism is defined as the coexistence of clinical features compatible with androgen deficiency and lowered serum testosterone that occur in the absence of intrinsic structural HPT axis pathology (e.g. Klinefelter's syndrome, pituitary tumour) and the absence of specific pathologic conditions suppressing the HPT axis (e.g. prolactinoma, Cushing's syndrome). Functional hypogonadism is a diagnosis of exclusion and in contrast to organic hypogonadism, potentially reversible. Functional hypogonadism, in older men also referred to as late-onset hypogonadism, is not uncommon, with a population prevalence of $2.1 \%$ by stringent diagnostic criteria. The prevalence increases with age, occurring in
$0.6 \%$ of men aged $50-59$ years, rising to $5.1 \%$ in men aged 70-79 years (3).

While testosterone replacement in organic hypogonadism is uncontroversial, the role of testosterone treatment in middle-aged to older men with functional hypogonadism remains debated and controversial. This is largely because definitive clinical trials designed and powered to provide conclusive evidence regarding patientimportant long-term health benefits - and potential risks - of testosterone therapy are currently lacking.

In this debate, we address this controversy and present two opposing views on the role of testosterone therapy in older man with functional hypogonadism. This debate explores arguments for and against the role of testosterone treatment, framed around a typical clinical case. While this case may not cover all the nuances of clinical management arising in individual patients, the case is nevertheless representative of the main issues that the clinician typically encounters. Specifically, the effects of testosterone treatment on constitutional and on sexual,

Published by Bioscientifica Ltd. 
cardiometabolic and bone health, as well as the authors' perspective of potential risks, are discussed.

\section{The case}

A 67-year-old man consults you to seek your advice regarding testosterone treatment. His main concerns are that of fatigue, low libido, and erectile dysfunction. Since retirement from his accountancy firm 12 months earlier, he reports that his energy levels have worsened gradually. He feels 'washed out' several days a week and, at times, needs to force himself to do his usual daily activities. Over the years, his erections have gradually become less firm, and he reports reduced morning erections. He rates his sexual desire as low. He has tried a phosphodiesterase-5 inhibitor (Sildenafil $25 \mathrm{mg}$ ) a couple of times, with limited success. He attempts sexual intercourse weekly and reports that they are pleasurable in about one-third of attempts and limited by insufficient erection, and at times by premature ejaculation.

He has controlled hypertension treated with dual therapy (ACE inhibitor and calcium channel blocker), hypercholesteraemia treated with a statin, and ischaemic heart disease treated with aspirin. He suffered a non-ST elevation myocardial infarction 3 years ago which was treated with a drug-eluting stent. He reports no cardiac symptoms since, and an exercise stress echo performed 6 months ago was normal. He is a former cigarette smoker (30 pack-year history). He drinks about 1-2 glasses of wine per week. He reports no symptoms suggestive of sleep apnea. He reports that over the years, his urinary stream has weakened and reports occasional urinary urgency but denies nocturia or any lower urinary tract symptoms (LUTS).

He lives with his wife, who is accepting of his low sexual drive, and they have two adult children and three grandchildren who live interstate. He plays golf about twice a month but does not feel motivated to engage in regular exercise. He has tried a variety of diets to lose weight, including several attempts at following a formal very low-energy diet supervised by a qualified dietician, without sustained success.

On physical examination, his BMI is $31.4 \mathrm{~kg} / \mathrm{m}^{2}$ and his waist circumference is $102 \mathrm{~cm}$. Blood pressure is $132 / 84$ $\mathrm{mm} \mathrm{Hg}$. Cardiac exam is normal. He has normal malepattern body hair. He has normal penile length, and testes are $20 \mathrm{~mL}$ bilaterally. There is a slight loss of muscle bulk. There is no gynecomastia or clinical evidence of a pituitary mass lesion, with no clinical visual field defect, and a full range of eye movements. Rectal exam reveals no prostatic abnormality.
Laboratory test results (sample drawn at 8:00 h while fasting)

Total testosterone is $8.3 \mathrm{nmol} / \mathrm{L}$ (reference range 10.4-31.2 $\mathrm{nmol} / \mathrm{L}$ ), repeated measurement 1 week later $9.1 \mathrm{nmol} / \mathrm{L}$. SHBG is $18 \mathrm{nmol} / \mathrm{L}(10-60 \mathrm{nmol} / \mathrm{L})$. Calculated free testosterone is $218 \mathrm{pmol} / \mathrm{L}(310-1004 \mathrm{pmol} / \mathrm{L})$, repeat 240 pmol/L. LH is $4.9 \mathrm{IU} / \mathrm{L}(1.0-10.0 \mathrm{IU} / \mathrm{L})$ and FSH $3.6 \mathrm{mIU} /$ $\mathrm{mL}$ (1.0-10.0 IU/L). Prolactin, thyroid function, and iron studies are normal, with the exception of a mildly raised ferritin of $230 \mu \mathrm{g} / \mathrm{L}(20-200 \mu \mathrm{g} / \mathrm{L})$.

Fasting glucose is $6.3 \mathrm{mmol} / \mathrm{L}$ and Hba1c $6.2 \%(44$ $\mathrm{mol} / \mathrm{mol}$ ). Total cholesterol is $3.9 \mathrm{nmol} / \mathrm{L}$, HDL cholesterol $0.8 \mathrm{nmol} / \mathrm{L}$, LDL cholesterol $2.2 \mathrm{nmol} / \mathrm{L}$, and triglycerides are $2.6 \mathrm{nmol} / \mathrm{L}$.

Haemoglobin is $140 \mathrm{~g} / \mathrm{L}(130-180)$ and alanine aminotransferase (ALT) $52 \mathrm{U} / \mathrm{L}(10-40 \mathrm{U} / \mathrm{L})$. Prostatespecific antigen (PSA) is $2.2 \mu \mathrm{g} / \mathrm{L}(<5.3 \mu \mathrm{g} / \mathrm{L})$.

His primary health care provider has performed dualenergy X-ray absorptiometry (DXA) scanning and his T-scores at the lumbar spine and femoral neck are -1.6 . and -1.1 , respectively.

\section{Should he be offered testosterone treatment?}

\section{Against treatment (M Grossman)}

\section{Constitutional symptoms and sexual health}

This man presents with non-specific symptoms including fatigue, low energy and low motivation. In the European Male Ageing Study (EMAS), there was no syndromic association between fatigue and serum testosterone (3). In the testosterone trials (T-Trials), a large RCT of 790 men aged 65 years and older with serum testosterone of $<9.5$ $\mathrm{nmol} / \mathrm{L}$, testosterone treatment did not improve vitality (4). Therefore, his fatigue and low energy are not expected to improve with testosterone therapy. These symptoms are likely multifactorial. They may be linked to his recent retirement. He should be screened for depression, and other potential contributors to his non-specific symptoms, such as obstructive sleep apnoea (denial of symptoms does not reliably exclude sleep apnoea), should be explored.

With respect to sexual function, a recent meta-analysis restricted to rigorous RCTs enrolling men with serum testosterone of $<10.4 \mathrm{nmol} / \mathrm{L}$ and at least one symptom of hypogonadism reported that testosterone treatment was associated with significant increases in libido (standardised mean difference (SMD): 0.17), erectile function (SMD: 0.16), and sexual satisfaction (SMD: 0.16) (5). In the T-Trials, 
testosterone treatment was associated with improvements in all aspects of sexual dysfunction, with SMDs up to 0.45 (4). In general, SMDs of $\leq 0.2$ are considered to represent small, and SMDs of 0.2-0.5 to represent modest treatment effects. Regarding erectile dysfunction, in a comprehensive meta-analysis of 14 testosterone RCTs including 2298 men with serum testosterone of $<12 \mathrm{nmol} / \mathrm{L}$, the testosterone treatment-associated increase in the International Index of Erectile Function (IIEF) score was 3.0 in men with serum testosterone of $<8 \mathrm{nmol} / \mathrm{L}$ and 1.5 in those with testosterone of $8-12 \mathrm{nmol} / \mathrm{L}$ (6). In the T-Trials, the increase in the IIEF score was 2.6 (4). Overall, mean testosterone therapy-associated increases in IIEF scores were consistently less than 4.0, which is considered the minimal clinically important difference (7). By contrast, in an RCT of 140 men with erectile dysfunction and serum testosterone of less than $11.4 \mathrm{nmol} / \mathrm{L}$, phosphodiesterase 5-inhibitor (PDE5-inhibitor) treatment increased the IIEF score by 7.7 compared to placebo, a clinically meaningful effect (8). This increase is in line with a large meta-analysis of PDE5-inhibitor RCTs including 31,195 men with erectile dysfunction (9), and with an RCT in the geriatric population (10) reporting increases in the IIEF score of 6.6 (9), and 5.7 (10), respectively. In the most rigorous RCT enrolling men with low serum testosterone, testosterone treatment did not further improve sexual function in men in whom the sexual function was optimised with a PDE5inhibitor (8). This man has not had an adequate course of PDE5-inhibitor treatment. His PDE5-inhibitor treatment should be carefully uptitrated to the highest tolerated dose, and, once PDE5-inhibitor treatment has been optimised, testosterone treatment is unlikely to provide additional clinically meaningful benefits that would justify testosterone treatment. Of note, medical claims database analyses of men initiating testosterone treatment for nonspecific hypogonadal diagnoses report that only about a third of men continue testosterone treatment beyond 6 months, and less than $20 \%$ beyond 1 year, with an average treatment duration of $4-5$ months $(11,12)$. While the reasons for low adherence are not fully understood, it is quite possible that perceived low efficacy and/or unrealistic patient expectations regarding the benefits of treatment may play a role.

\section{Cardiometabolic health}

This man is obese, at risk of diabetes and given his established cardiovascular disease, his LDL cholesterol is not a target. Testosterone treatment has been associated with modest changes in body composition, a decrease in fat mass and an increase in muscle mass by about $2 \mathrm{~kg}$, changes that are expected to be metabolically favourable (13). In the largest testosterone RCT to date, T4DM, which randomised to 1007 men long-acting, injectable testosterone undecanoate treatment or placebo over 2 years, testosterone treatment was associated with a $40 \%$ relative risk reduction in type 2 diabetes incidence, based on the primary endpoint, the 2-h glucose after an oral glucose tolerance test (14). However, in this RCT, the effect on the 2-h glucose was modest (a mean difference of $-0.75 \mathrm{mmol}$ in the testosterone group vs placebo). In T4DM, testosterone treatment had no significant effect on $\mathrm{HbA1c}$, or on body weight (14), findings in line with the aforementioned T-Trials (15). Reported effects of testosterone treatment on serum lipids are relatively minor and of uncertain clinical significance, as small decreases in LDL ( 0.059 $\mathrm{mmol} / \mathrm{L})$ but also in HDL cholesterol ( 0.051 $\mathrm{mmol} / \mathrm{L})$ have been reported $(13,15)$. Effects of testosterone treatment on cardiovascular events are uncertain, as it has been estimated that a placebo-controlled testosterone RCT with $>10,000$ men in each arm would be required to detect a true difference in cardiovascular events (16), while the largest RCTs to date enrolled a total of 790-1007 men $(4,14)$. In this patient, cardiometabolic health is best optimised with lifestyle measures aiming for weight loss, which can lead to large increases in serum testosterone in obese men (17), and with optimisation of statin therapy. In addition, in contrast to testosterone treatment, antiglycaemic agents such as glucagon-like peptide-1 (GLP-1) receptor agonists and sodium-glucose co-transporter-2 (SGLT2) inhibitors not only consistently improve HbA1c but also lead to weight loss and, especially in men with pre-existing cardiovascular disease, have established cardiovascular benefits (18).

\section{Bone health}

This patient has modest osteopenia. Of note, in the T-Trials bone sub-study, among men with a baseline serum testosterone of approximately $8.2 \mathrm{nmol} / \mathrm{L}$, baseline bone density was normal (19). This is consistent with observational studies reporting that bone health is compromised only if serum testosterone is $<6.9-8.7 \mathrm{nmol} / \mathrm{L}$ (20); therefore this patient's modestly reduced serum testosterone is unlikely to be a major rectifiable contributor to his osteopaenia. Hence, other contributing factors, such as vitamin D deficiency, or lack of weight-bearing exercise, should be explored and treated as appropriate. While testosterone treatment has been reported to robustly increase bone mineral density (BMD) (19) and to 
improve bone microarchitecture (21) with effects similar in magnitude to that reported for osteoporotic drug therapy in postmenopausal women, RCTs have not been large enough to determine whether testosterone treatment reduces fracture risk. Of note in the T-Trials, testosteroneand placebo-treated men had an identical frequency of falls (27\% in each group) (22), a common precipitant of - especially femoral - fragility fractures in older men. In summary, while testosterone treatment is likely to improve this man's BMD, this would not, in absence of fracture data, be a sufficient reason to treat with testosterone. This is in line with current Endocrine Society Osteoporosis in Men Clinical Practice guidelines that recommend that men at high risk of fracture should receive osteoporotic drug therapy with proven anti-fracture effects (20). The guidelines recommend testosterone treatment for bone health only if osteoporotic drug therapy is contraindicated, and serum testosterone is repeatedly $<6.9 \mathrm{nmol} / \mathrm{L}$, which is not the case for our patient (20).

\section{Potential harms}

Compared to placebo, testosterone treatment is associated with an eight-fold increase in developing erythrocytosis (5). In T4DM, 22\% (106/491) of testosterone-treated men experienced a haematocrit of $>0.54$, compared to $1 \%$ of placebo-treated men (14). Of note, however, of those 106 men, only 25 men (5\% of total testosteronetreated men) had a haematocrit of $>0.54$ on repeat testing, leading to withdrawal from the study (14). In the T-Trials, erythrocytosis was reported in 1.8\% (7/394) of testosterone-treated men (4), similar to the incidence of $1.6 \%(6 / 358)$ in testosterone-treated men in another large RCT by Brock et al. (23). The higher rate of erythrocytosis in T4DM compared to the two other large RCTs is not entirely clear. Possible explanations include the longer duration of testosterone treatment in T4DM, 2 years compared to 1 year in the T-Trials (4) and 4 months in Brocks' study (23). Further, in T4DM, injectable testosterone undecanoate was used (14), whereas the two other large RCTs used topical testosterone $(4,23)$. Finally, in T4DM, testosterone undecanoate was given for 3-monthly, without dose adjustments, and no systematic screening for underlying risk factors for erythrocytosis (e.g. sleep apnoea, lung disease) was performed (14). While an increased haematocrit has been associated with an increased risk of cardiovascular events, the true cardiovascular effects of testosterone treatment on hard clinical outcomes remain unknown, due to the lack of appropriately designed and powered clinical trials. Two large observational studies have associated testosterone treatment with an increased risk of venous thromboembolic events (VTE) $(24,25)$. The US Federal Drug Administration, in addition to a cardiovascular warning, requires a testosterone products label warning of increased VTE risk both as a possible consequence of erythrocytosis and independent of erythrocytosis. Regarding prostate risk, while there is no evidence suggesting that testosterone increases the risk of prostate cancer, definitive outcome trials are lacking. It has been estimated that a 5-year RCT randomising 6000 men is required to detect a $30 \%$ difference in clinical prostate cancer (26), yet the largest RCT enrolled 1007 men over 2 years (14). Given the prostate is an androgendependent organ, testosterone treatment increases serum PSA, which may increase the risk of a prostate biopsy (27), and potentially, lead to over-diagnosis of pre-existing, clinically insignificant, prostate cancer. While testosterone treatment does not appear to worsen symptoms of prostate hypertrophy, men with significant obstructive symptoms were excluded from testosterone trials. Finally, testosterone therapy has been associated with a temporary worsening of obstructive sleep apnoea (28).

\section{Recommendation summary}

Based on the current evidence from clinical trials, testosterone treatment will not improve this man's fatigue and low energy. His sexual dysfunction, especially his erectile dysfunction, should improve with uptitration of PDE5-inhibitor therapy. Testosterone treatment, while it may increase libido and other aspects of sexual function by a small amount, is unlikely to provide clinically meaningful benefits once his sexual function has been optimised with PDE5-inhibitor therapy. With respect to his cardiometabolic health, testosterone treatment may lead to modest improvements in body composition, may improve insulin resistance and reduce diabetes risk, but, in RCTs, it has not been shown to reduce body weight or HbA1c. Effects on serum lipids are minor. Testosterone treatment will increase BMD, but has no effect on fall risks, and fracture outcomes are unknown. Potential risks include an increase in haematocrit, while effects on long-term cardiovascular outcomes and prostate risks remain unknown. Therefore, I would not recommend testosterone treatment in this man. Instead, I would focus on a holistic care approach which includes screening for depression, sleep apnoea, implementation of lifestyle measures including weight loss, and treatment of cardiometabolic risk with established 
medical therapy, that is, intensification of statin therapy, and if indicated anti-glycaemic drug with established patient-important outcomes (e.g. GLP-1 agonists and SGLT-2 inhibitor therapy). However, given potential benefits of testosterone therapy in older men in multiple domains, the outcome of future clinical trials, especially of the TRAVERSE trial (NCT03518034) an ongoing 5-year trial of testosterone treatment aiming to recruit 6000 men, is awaited with interest.

\section{For treatment (T H Jones)}

Constitutional symptoms and sexual health

Clinical guidelines and consensus documents state that the three major symptoms of sexual dysfunction loss or reduction of libido and morning erections and erectile dysfunction are symptoms of hypogonadism $(1,29,30)$. EMAS found that these three sexual symptoms had a syndromic association with serum testosterone below a threshold of approximately $11 \mathrm{nmol} / \mathrm{L}$ (3). Guidelines also include physical (e.g. fatigue, tiredness, reduced muscular strength and endurance) and psychological (e.g. grumpiness, irritability, low mood, reduced motivation) symptoms which are very important but are non-specific to a diagnosis of testosterone deficiency. It is accepted that these symptoms of sexual dysfunction, physical and psychological health can be caused by other conditions which, for example, include depression, neurosis, chronic pain and impaired cardiovascular health. Questionnaires are used in the assessment of patients which are good to capture individual patient symptoms but should not be used as a diagnostic tool as they have low sensitivity and specificity. They can be used to help assess clinical improvement in individual patients. Guidelines also suggest that patients can be given a trial of testosterone therapy of at least 6 months to assess any benefit or not (29).

There is good evidence from the larger RCTs $(n=180$ to 1007) that testosterone replacement improves sexual health of hypogonadal men with metabolic syndrome, type 2 diabetes and older age $(14,31,32,33)$. These studies include the TIMES2 (metabolic syndrome \pm type 2 diabetes) (32), BLAST (type 2 diabetes) (33), T4DM (prediabetes) (14), Moscow study (metabolic syndrome) (31) and T-Trials (older men) (4) as assessed by either the IIEF or the Psychosexual Daily Questionnaire. It is also known that PDE5-inhibitor action is reduced in the presence of testosterone deficiency and that testosterone therapy can convert approximately 60\% of PDE5-inhibitor nonresponders to responders $(34,35)$.
Assessment of physical and psychological symptoms and quality of life due to the heterogeneity of the populations studied has produced mixed results. The T-Trial reported improvements in physical function (22) and slightly better mood with testosterone treatment (4), but no benefit on vitality and fatigue scores (4). The BLAST study reported benefits in quality of life in men who were not depressed but not with those with depression (33).

\section{Cardiometabolic health}

Testosterone deficiency is associated with an adverse effect on cardiovascular risk factors which include truncal obesity, dyslipidaemia, hyperglycaemia and insulin resistance and a pro-inflammatory milieu (36). Testosterone deficiency is also associated with increased mortality of greater than two-fold from all-cause and cardiovascular disease in community-dwelling populations and in men with specific diseases including diabetes and coronary artery stenosis $(37,38,39,40)$. Metabolic syndrome also has independently a very high risk of future cardiovascular events and mortality (41).

Our patient has hypogonadism after adequate treatment of his hypertension and hypercholesterolaemia. He has prediabetes which is an independent cardiovascular risk factor currently treated with lifestyle improvement but apart from consideration of metformin has no other specific treatment. He has not managed to achieve sustained weight loss with diet alone. A $10 \%$ weight loss in RCTs is required to raise the testosterone by $3 \mathrm{nmol} / \mathrm{L}(42)$. Even if he had managed to achieve this weight reduction, his serum testosterone would only be $11.3 \mathrm{nmol} / \mathrm{L}$ with a free testosterone in the lower normal range. These levels are not likely to be sufficient to result in the resolution of his symptoms of testosterone deficiency.

His coronary artery stenosis has been treated with stenting. It is known that angioplasty and stenting do not increase testosterone levels (43). There are no clinical management strategies for his cardiovascular disease or risk factors that are currently known to improve his testosterone status. He already has had a myocardial infarction so with low testosterone he has a two-fold increased risk of mortality compared to a man with coronary disease and normal testosterone. There is evidence from RCTs that testosterone replacement can improve insulin resistance, reduce percent body fat and central obesity (44). In addition, long duration epidemiological studies have found that testosterone therapy reduces mortality in T2D (38). 


\section{Bone health}

Testosterone deficiency is a major cause of osteoporosis and low trauma fracture in men (1). In this patient, the DXA reports that he has osteopaenia which could potentially develop into osteoporosis in the future with consequent increased risk of fractures. Osteopaenia can be treated with improved lifestyle, vitamin $\mathrm{D}$ and calcium, and if he develops osteoporosis, other therapies such as bisphosphonates may be added. There is evidence from the T-Trials that testosterone replacement improves volumetric bone density and estimated bone strength in the lumbar vertebrae and the hip (19). The benefits were greatest in the lumbar spine and trabecular bone (19). There is no evidence from clinical trials at present that testosterone therapy reduces fracture rates in men. Although osteopaenia is not an indication alone to commence testosterone therapy this would be an added advantage to the treatment of his symptoms of testosterone deficiency.

\section{Potential harms}

It is very important that patients are given a good clear explanation of their diagnosis and that they are told that symptoms can take up to 6 months to resolve. The medical professional should also make it clear that lifestyle management with weight loss and increased physical activity if possible are integral to the therapeutic plan. This is time well spent and does help to manage patient expectations. Ideally, the formulation of testosterone prescribed should aim to replace testosterone as near as possible to normal serum testosterone levels. The formulations that are most likely to achieve this currently in Europe are either gels (peak testosterone measured 2 to $4 \mathrm{~h}$ after application, mid to upper normal range) or long-acting intra-muscular testosterone undeconoate (trough testosterone level $12-15 \mathrm{nmol} / \mathrm{L}$ ). Monitoring with regular review of the serum testosterone and safety parameters, for example, haematocrit and PSA allows review of adequate replacement and safety $(1,29,30)$. It is well known that one of the natural biological actions of testosterone is to stimulate erythropoiesis. It is accepted in guidelines that an elevation of haematocrit up to and including 0.54 has no adverse effect clinically (1, 29, 30). Testosterone replacement can in a small proportion of more sensitive patients (2-5\%) result in significant secondary polycythaemia. If sensitivity does occur, it is usually evident within the first 12 months. There is no evidence from RCT's that secondary polycythaemia due to testosterone therapy is associated with adverse outcomes
(30). However, polycythaemia can be managed in the vast majority of men on testosterone therapy by reducing the dose, switching formulations (e.g. injections to gels) and if required, venesections (30). In some cases, the testosterone treatment may need to be temporarily stopped.

There have been some concerns in regard to cardiovascular safety; however, no increase in major adverse cardiovascular events (MACE) have been reported in RCT's of up to 3 years where testosterone was replaced to normal levels and were within licensed dosing $(1,30,45)$. The majority of longer-term registry studies have reported a reduction in MACE. Those studies that have found an increase in cardiovascular events occurred with testosterone treatment have been shown to have several study flaws. The TRAVERSE study, a large 5-year RCT of testosterone vs placebo has been designed to provide definitive evidence on safety. Treatment of coronary atherosclerosis with angioplasty and stenting has no benefit on testosterone levels (43). Testosterone replacement leads to improvement in moderate congestive cardiac failure but overtreatment can cause fluid retention $(46,47)$.

There is no evidence that testosterone therapy causes prostate carcinoma $(1,30)$. Some recent epidemiological studies have reported that testosterone replacement is associated with reductions in prostate cancer rates (30). If occult cancer has not been identified prior to commencing therapy, then the tumour may be unmasked (usually evident within the first 9 months) by testosterone allowing early diagnosis (30).

There are significant potential harms to not treating a man with hypogonadism which include continuing poor health and quality of life, depression, job loss, marriage/ partner separation, increased risk of diabetes, osteoporosis and increased risk of premature death.

\section{Recommendation summary}

I would offer this man testosterone replacement therapy after consideration of the benefits vs risks of treatment. Importantly, the patient had significant medical problems for him to arrange a consultation to discuss them with a doctor. He presents with classical symptoms which encompass disturbance in sexual, physical and psychological health. These symptoms are adversely affecting his quality of life associated with reduced motivation, in particular, resulting in reduced exercise and the inability to lose weight. He has a diagnosis of hypogonadism with appropriate symptoms and biochemical evidence on the investigation with two low 
fasting testosterone levels. This diagnosis is supported by low-calculated free testosterone and inappropriately lownormal gonadotropins.

He has metabolic syndrome with the five key elements (visceral obesity, hypertension, impaired fasting glucose, low HDL cholesterol and raised triglycerides). He already has a significant cardiovascular disease with a history of a non-ST elevation myocardial infarction. So he is at increased risk of further MACE events including sudden cardiovascular death. His erectile dysfunction may be caused by atherosclerosis but testosterone deficiency is also likely to be a factor. In addition, he has osteopaenia with future risk of developing osteoporosis and also frailty.

\section{Conclusions}

In this debate, centered around a patient presenting with androgen deficiency-like symptoms and lowered testosterone, that is, functional hypogonadism, we have presented our reasoning why we would not or why we would consider testosterone treatment. We have both emphasised the importance of lifestyle measures especially weight loss, which, if substantial and sustained, can lead to significant increases in testosterone. In one metaanalysis, $10 \%$ of weight loss (achieved by low-calorie diet) increased serum testosterone by $2.9 \mathrm{nmol} / \mathrm{L}$, and $32 \%$ weight loss (achieved by bariatric surgery) increased serum testosterone by $8.7 \mathrm{nmol} / \mathrm{L}$ (17). Weight loss can be associated with improvements in sexual and constitutional symptoms but in clinical practise, marked weight loss is difficult to achieve and sustain. Importantly, the case presented in this debate had failed several attempts to lose weight with lifestyle measures and formal diet programs. It is possible that low testosterone may contribute to poor motivation, reducing the ability to engage in healthy lifestyle measures, although clinical studies supporting this concept are lacking.

One of us (MG) is not convinced that the presenting symptoms are necessarily causally related to his lowered serum testosterone. Therefore, he would favour reinforcing lifestyle advice to achieve healthy body weight, screening for and treating depression and sleep apnoea if present, and focus on targeted treatment for presenting concerns that are supported by high-level evidence for patientimportant outcomes, such as optimisation of PDE5inhibitor treatment for erectile dysfunction, optimisation of cardiometabolic health (intensification of statin therapy, and potentially the use of GLP-1 agonists and SGLT-2 inhibitor treatment). Testosterone treatment may well have modest benefits on some aspects of sexual function (although this has not been unequivocally shown in men whose sexual function has been optimised with PDE5inhibitor treatment), and on bone density, and may slightly improve mood, although there is no evidence it improves major depressive disorders. In addition, testosterone treatment improves anaemia and modestly improves walking distance in men with mobility limitations, but these aspects are currently not relevant for this case. Of note, while current data are somewhat reassuring, the true long-term effects of testosterone treatment on prostate and cardiovascular outcomes remain unknown. On balance, therefore, given modest benefits, potential risks, and availability of alternative treatment, MG is not convinced that testosterone treatment would meaningfully improve overall health and quality of life for this man.

One of us (THJ) believes that is unlikely this man's symptoms will respond to lifestyle advice and/or any strategy to optimise his cardiovascular disease. He came to the doctor seeking medical advice about several symptoms which are clearly adversely affecting his quality of life. His symptoms are non-specific but in the presence of his low testosterone levels, fulfil the diagnostic criteria for hypogonadism. He has already tried several diets and physical exercise without success but has low motivation. Clinical trials have shown that lifestyle advice can result in small increases in testosterone with $10 \%$ weight loss; however, in normal practise, most patients struggle to lose $5 \%$ body weight. He has metabolic syndrome and already has established cardiovascular disease. There is no treatment for the underlying atherosclerosis which normalises testosterone. Testosterone deficiency promotes fat accumulation and he is at high risk of progressing from prediabetes to overt type 2 diabetes. Importantly evidence shows that testosterone therapy reduces this risk. He may respond to higher doses of sildenafil; however, PDE-5 inhibitors have reduced efficacy in testosterone deficiency but replacement can improve sildenafil response. Guidelines support a 6-month testosterone replacement trial with careful monitoring. The patient should be fully informed of potential risks prior to agreeing to the trial. Based on current evidence and clinical practise, THJ would offer him a trial of testosterone therapy.

The controversy outlined here is reflected in testosterone treatment guidelines, with some guidelines recommending against testosterone treatment in men with functional hypogonadism (48), while others suggest individualised treatment without specifying serum testosterone cutoffs (1), while others support testosterone treatment for testosterone concentrations of less than 
8-12 nmol/L (30). Of note, we both emphasise that this is a moving field, and the outcome of the TRAVERSE trial (NCT03518034), a large testosterone trial with a recruitment target of 6000 men, is awaited with interest. In the meantime, clinicians must use their own judgment in applying the available data into their clinical management decisions, taking into consideration patient preferences, to optimise the overall health of their patients. Finally, it should be emphasised that testosterone replacement in men with organic hypogonadism is uncontroversial (unless fertility is desired), and that organic hypogonadism is underdiagnosed and undertreated.

\section{Declaration of interest}

M G has received research funding from Bayer Healthcare, Otzuka, and speaker's honoraria from Besins Health Care and Novartis. T H J has received research grants, lecture and advisory board fees from Bayer Healthcare and Besins Healthcare and consultancy fees from Medac Pharma and Mereo Biopharma.

\section{Funding}

The writing of this article did not receive any specific grant from any funding agency in the public, commercial or not-for-profit sector.

\section{References}

1 Bhasin S, Brito JP, Cunningham GR, Hayes FJ, Hodis HN, Matsumoto AM, Snyder PJ, Swerdloff RS, Wu FC \& Yialamas MA. Testosterone therapy in men with hypogonadism: an Endocrine Society clinical practice guideline. Journal of Clinical Endocrinology and Metabolism 2018103 1715-1744. (https://doi.org/10.1210/jc.2018-00229)

2 Grossmann M \& Matsumoto AM. A perspective on middle-aged and older men with functional hypogonadism: focus on holistic management. Journal of Clinical Endocrinology and Metabolism 2017 102 1067-1075. (https://doi.org/10.1210/jc.2016-3580)

3 Wu FC, Tajar A, Beynon JM, Pye SR, Silman AJ, Finn JD, O'Neill TW, Bartfai G, Casanueva FF, Forti G et al. Identification of late-onset hypogonadism in middle-aged and elderly men. New England Journal of Medicine 2010363 123-135. (https://doi.org/10.1056/NEJMoa0911101)

4 Snyder PJ, Bhasin S, Cunningham GR, Matsumoto AM, StephensShields AJ, Cauley JA, Gill TM, Barrett-Connor E, Swerdloff RS, Wang C et al. Effects of testosterone treatment in older men. New England Journal of Medicine 2016374 611-624. (https://doi.org/10.1056/NEJMoa1506119)

5 Ponce OJ, Spencer-Bonilla G, Alvarez-Villalobos N, Serrano V, Singh-Ospina N, Rodriguez-Gutierrez R, Salcido-Montenegro A, Benkhadra R, Prokop LJ, Bhasin S et al. The efficacy and adverse events of testosterone replacement therapy in hypogonadal men: a systematic review and meta-analysis of randomized, placebo-controlled trials. Journal of Clinical Endocrinology and Metabolism 2018103 1745-1754. (https://doi.org/10.1210/jc.2018-00404)

6 Corona G, Rastrelli G, Morgentaler A, Sforza A, Mannucci E \& Maggi M. Meta-analysis of results of testosterone therapy on sexual function based on international index of erectile function scores. European Urology 2017 72 1000-1011. (https://doi.org/10.1016/j.eururo.2017.03.032)

7 Rosen RC, Allen KR, Ni X \& Araujo AB. Minimal clinically important differences in the erectile function domain of the International Index of Erectile Function scale. European Urology 201160 1010-1016. (https://doi.org/10.1016/j.eururo.2011.07.053)
8 Spitzer M, Basaria S, Travison TG, Davda MN, Paley A, Cohen B, Mazer NA, Knapp PE, Hanka S, Lakshman KM et al. Effect of testosterone replacement on response to sildenafil citrate in men with erectile dysfunction: a parallel, randomized trial. Annals of Internal Medicine 2012157 681-691. (https://doi.org/10.7326/0003-4819-15710-201211200-00004)

9 Yuan J, Zhang R, Yang Z, Lee J, Liu Y, Tian J, Qin X, Ren Z, Ding H, Chen $Q$ et al. Comparative effectiveness and safety of oral phosphodiesterase type 5 inhibitors for erectile dysfunction: a systematic review and network meta-analysis. European Urology 2013 63 902-912. (https://doi.org/10.1016/j.eururo.2013.01.012)

10 Muller A, Smith L, Parker M \& Mulhall JP. Analysis of the efficacy and safety of sildenafil citrate in the geriatric population. BJU International 2007100 117-121. (https://doi.org/10.1111/j.1464410X.2007.06915.x)

11 Schoenfeld MJ, Shortridge E, Cui Z \& Muram D. Medication adherence and treatment patterns for hypogonadal patients treated with topical testosterone therapy: a retrospective medical claims analysis. Journal of Sexual Medicine 201310 1401-1409. (https://doi.org/10.1111/jsm.12114)

12 Donatucci C, Cui Z, Fang Y \& Muram D. Long-term treatment patterns of testosterone replacement medications. Journal of Sexual Medicine 201411 2092-2099. (https://doi.org/10.1111/jsm.12608)

13 Isidori AM, Giannetta E, Greco EA, Gianfrilli D, Bonifacio V, Isidori A, Lenzi A \& Fabbri A. Effects of testosterone on body composition, bone metabolism and serum lipid profile in middle-aged men: a meta-analysis. Clinical Endocrinology 200563 280-293. (https://doi. org/10.1111/j.1365-2265.2005.02339.x)

14 Wittert G, Bracken K, Robledo KP, Grossmann M, Yeap BB, Handelsman DJ, Stuckey B, Conway A, Inder W, McLachlan R et al. Testosterone treatment to prevent or revert type 2 diabetes in men enrolled in a lifestyle programme (T4DM): a randomised, doubleblind, placebo-controlled, 2-year, phase $3 \mathrm{~b}$ trial. Lancet: Diabetes and Endocrinology 20219 32-45. (https://doi.org/10.1016/S22138587(20)30367-3)

15 Mohler ER, 3rd, Ellenberg SS, Lewis CE, Wenger NK, Budoff MJ, Lewis MR, Barrett-Connor E, Swerdloff RS, Stephens-Shields A, Bhasin S et al. The effect of testosterone on cardiovascular biomarkers in the testosterone trials. Journal of Clinical Endocrinology and Metabolism 2018103 681-688. (https://doi.org/10.1210/jc.2017-02243)

16 Onasanya O, Iyer G, Lucas E, Lin D, Singh S \& Alexander GC. Association between exogenous testosterone and cardiovascular events: an overview of systematic reviews. Lancet: Diabetes and Endocrinology 20164 943-956. (https://doi.org/10.1016/S22138587(16)30215-7)

17 Corona G, Rastrelli G, Monami M, Saad F, Luconi M, Lucchese M, Facchiano E, Sforza A, Forti G, Mannucci E et al. Body weight loss reverts obesity-associated hypogonadotropic hypogonadism: a systematic review and meta-analysis. European Journal of Endocrinology 2013168 829-843. (https://doi.org/10.1530/EJE-12-0955)

18 Marx N, Davies MJ, Grant PJ, Mathieu C, Petrie JR, Cosentino F \& Buse JB. Guideline recommendations and the positioning of newer drugs in type 2 diabetes care. Lancet: Diabetes and Endocrinology 20219 46-52. (https://doi.org/10.1016/S2213-8587(20)30343-0)

19 Snyder PJ, Kopperdahl DL, Stephens-Shields AJ, Ellenberg SS, Cauley JA, Ensrud KE, Lewis CE, Barrett-Connor E, Schwartz AV, Lee DC et al. Effect of testosterone treatment on volumetric bone density and strength in older men with low testosterone: a controlled clinical trial. JAMA Internal Medicine 2017177 471-479. (https://doi. org/10.1001/jamainternmed.2016.9539)

20 Watts NB, Adler RA, Bilezikian JP, Drake MT, Eastell R, Orwoll ES, Finkelstein JS \& Endocrine Society. Osteoporosis in men: an Endocrine Society clinical practice guideline. Journal of Clinical Endocrinology and Metabolism 201297 1802-1822. (https://doi.org/10.1210/jc.2011-3045)

21 Fui NT, M, Hoermann R, Bracken K, Handelsman DJ, Inder WJ, Stuckey BGA, Yeap BB, Ghasem-Zadeh A, Robledo KP et al. Effect of testosterone treatment on bone microarchitecture and bone mineral 
density in men: a two-year RCT. Journal of Clinical Endocrinology and Metabolism 2021. (https://doi.org/10.1210/clinem/dgab149)

22 Bhasin S, Ellenberg SS, Storer TW, Basaria S, Pahor M, StephensShields AJ, Cauley JA, Ensrud KE, Farrar JT, Cella D et al. Effect of testosterone replacement on measures of mobility in older men with mobility limitation and low testosterone concentrations: secondary analyses of the testosterone trials. Lancet: Diabetes and Endocrinology 20186 879-890. (https://doi.org/10.1016/S2213-8587(18)30171-2)

23 Brock G, Heiselman D, Maggi M, Kim SW, Rodriguez Vallejo JM, Behre HM, McGettigan J, Dowsett SA, Hayes RP, Knorr J et al. Effect of testosterone solution $2 \%$ on testosterone concentration, sex drive and energy in hypogonadal men: results of a placebo controlled study. Journal of Urology 2016195 699-705. (https://doi.org/10.1016/j.juro.2015.10.083)

24 Martinez C, Suissa S, Rietbrock S, Katholing A, Freedman B, Cohen AT $\&$ Handelsman DJ. Testosterone treatment and risk of venous thromboembolism: population based case-control study. BMJ 2016 355 i5968. (https://doi.org/10.1136/bmj.i5968)

25 Walker RF, Zakai NA, MacLehose RF, Cowan LT, Adam TJ, Alonso A \& Lutsey PL. Association of testosterone therapy with risk of venous thromboembolism among men with and without hypogonadism. JAMA Internal Medicine 2020180 190-197. (https://doi.org/10.1001/ jamainternmed.2019.5135)

26 Cunningham GR \& Toma SM. Clinical review: why is androgen replacement in males controversial? Journal of Clinical Endocrinology and Metabolism 201196 38-52. (https://doi.org/10.1210/jc.2010-0266)

27 Calof OM, Singh AB, Lee ML, Kenny AM, Urban RJ, Tenover JL \& Bhasin S. Adverse events associated with testosterone replacement in middle-aged and older men: a meta-analysis of randomized, placebocontrolled trials. Journals of Gerontology: Series A, Biological Sciences and Medical Sciences 200560 1451-1457. (https://doi.org/10.1093/ gerona/60.11.1451)

28 Hoyos CM, Killick R, Yee BJ, Grunstein RR \& Liu PY. Effects of testosterone therapy on sleep and breathing in obese men with severe obstructive sleep apnoea: a randomized placebo-controlled trial. Clinical Endocrinology 201277 599-607. (https://doi.org/10.1111/j.13652265.2012.04413.x)

29 Hackett G, Kirby M, Edwards D, Jones TH, Wylie K, Ossei-Gerning N, David J \& Muneer A. British Society for Sexual Medicine Guidelines on adult testosterone deficiency, with statements for UK practice. Journal of Sexual Medicine 201714 1504-1523. (https://doi.org/10.1016/j. jsxm.2017.10.067)

30 Salonia A, Bettocchi C, Carvalho J, Corona G, Jones TH, Kadioglu A, Martinez-Salamanca I, Minhas S, Serefoğlu EC \& Verze P. European Association of Urology sexual and reproductive health guideline, 2020. (available at: https://uroweb.org/guideline/sexual-and-reproductivehealth/)

31 Kalinchenko SY, Tishova YA, Mskhalaya GJ, Gooren LJ, Giltay EJ \& Saad F. Effects of testosterone supplementation on markers of the metabolic syndrome and inflammation in hypogonadal men with the metabolic syndrome: the double-blinded placebo-controlled Moscow study. Clinical Endocrinology 201073 602-612. (https://doi.org/10.1111/ j.1365-2265.2010.03845.x)

32 Jones TH, Arver S, Behre HM, Buvat J, Meuleman E, Moncada I, Morales AM, Volterrani M, Yellowlees A, Howell JD et al. Testosterone replacement in hypogonadal men with type 2 diabetes and/or metabolic syndrome (the TIMES2 Study). Diabetes Care 201134 828-837. (https://doi.org/10.2337/dc10-1233)

33 Hackett G, Cole N, Bhartia M, Kennedy D, Raju J \& Wilkinson P. Testosterone replacement therapy with long-acting testosterone undecanoate improves sexual function and quality-of-life parameters vs. placebo in a population of men with type 2 diabetes. Journal of Sexual Medicine 201310 1612-1627. (https://doi.org/10.1111/jsm.12146)
34 Kalinchenko SY, Kozlov GI, Gontcharov NP \& Katsiya GV. Oral testosterone undecanoate reverses erectile dysfunction associated with diabetes mellitus in patients failing on sildenafil citrate therapy alone. Aging Male 2003 694-99. (https://doi.org/10.1080/tam.6.2.94.99)

35 Greenstein A, Mabjeesh NJ, Sofer M, Kaver I, Matzkin H \& Chen J. Does sildenafil combined with testosterone gel improve erectile dysfunction in hypogonadal men in whom testosterone supplement therapy alone failed? Journal of Urology 2005173 530-532. (https:// doi.org/10.1097/01.ju.0000149870.36577.05)

36 Jones TH, Howell J \& Channer KS. Testosterone improves glycaemic control, insulin resistance, body fat and sexual function in men with metabolic syndrome and/or type 2 diabetes: a multicentre European clinical trial. The TIMES2 study. Endocrine Abstract 201021 OC1.

37 Zarotsky V, Huang MY, Carman W, Morgentaler A, Singhal PK, Coffin D \& Jones TH. Systematic literature review of the risk factors, comorbidities, and consequences of hypogonadism in men. Andrology 20142 819-834. (https://doi.org/10.1111/andr.274)

38 Muraleedharan V, Marsh H, Kapoor D, Channer KS \& Jones TH. Testosterone deficiency is associated with increased risk of mortality and testosterone replacement improves survival in men with Type 2 diabetes. European Journal of Endocrinology 2013169 725-733. (https:// doi.org/10.1530/EJE-13-0321)

39 Muraleedharan V \& Jones TH. Testosterone and mortality. Clinical Endocrinology 201481 477-487. (https://doi.org/10.1111/cen.12503)

40 Malkin CJ, Pugh PJ, Morris PD, Asif S, Jones TH \& Channer KS. Low serum testosterone and increased mortality in men with coronary heart disease. Heart 201096 1821-1825. (https://doi.org/10.1136/ hrt.2010.195412)

41 Isomaa B, Almgren P, Tuomi T, Forsen B, Lahti K, Nissen M, Taskinen MR \& Groop L. Cardiovascular morbidity and mortality associated with the metabolic syndrome. Diabetes Care 200124 683-689. (https://doi.org/10.2337/diacare.24.4.683)

42 Grossmann M. Low testosterone in men with type 2 diabetes: significance and treatment. Journal of Clinical Endocrinology and Metabolism 201196 2341-2353. (https://doi.org/10.1210/jc.2011-0118)

43 Gosai JN, Charalampidis P, Nikolaidou T, Parviz Y, Morris PD, Channer KS, Jones TH \& Grech ED. Revascularization with percutaneous coronary intervention does not affect androgen status in males with chronic stable angina pectoris. Andrology 20164 486-491. (https://doi.org/10.1111/andr.12189)

44 Corona G, Giagulli VA, Maseroli E, Vignozzi L, Aversa A, Zitzmann M, Saad F, Mannucci E \& Maggi M. THERAPY OF ENDOCRINE DISEASE: Testosterone supplementation and body composition: results from a meta-analysis study. European Journal of Endocrinology $2016 \mathbf{1 7 4}$ R99-R116. (https://doi.org/10.1530/EJE-15-0262)

45 Corona G, Rastrelli G, Di Pasquale G, Sforza A, Mannucci E \& Maggi M. Testosterone and cardiovascular risk: meta-analysis of interventional studies. Journal of Sexual Medicine 201815 820-838. (https://doi. org/10.1016/j.jsxm.2018.04.641)

46 Malkin CJ, Pugh PJ, West JN, van Beek EJ, Jones TH \& Channer KS. Testosterone therapy in men with moderate severity heart failure: a double-blind randomized placebo controlled trial. European Heart Journal 200627 57-64. (https://doi.org/10.1093/eurheartj/ehi443)

47 Jones TH \& Kelly DM. Randomized controlled trials - mechanistic studies of testosterone and the cardiovascular system. Asian Journal of Andrology 201820 120-130. (https://doi.org/10.4103/aja.aja_6_18)

48 Yeap BB, Grossmann M, McLachlan RI, Handelsman DJ, Wittert GA, Conway AJ, Stuckey BG, Lording DW, Allan CA, Zajac JD et al. Endocrine Society of Australia position statement on male hypogonadism (Part 1): assessment and indications for testosterone therapy. Medical Journal of Australia 2016205 173-178. (https://doi. org/10.5694/mja16.00393)

Received 7 April 2021

Revised version received 12 June 2021

Accepted 14 July 2021 